\title{
Pulsed Telecommunication Signals of Non-ionizing Radiation Affect Amyloid Precursor Protein and $\alpha$-Synuclein Metabolism in Non-neural Human Cells
}

\author{
Aikaterina L. Stefi ${ }^{1,2}$, Aikaterini S. Skouroliakou ${ }^{3}$, Lukas H. Margaritis ${ }^{2, *}$ and \\ Dido Vassilacopoulou ${ }^{1}$ \\ 1 Department of Biochemistry and Molecular Biology, National and Kapodistrian University of Athens, 15784 \\ Athens, Greece, \\ 2 Department of Cell Biology and Biophysics, National and Kapodistrian University of Athens, 15784 Athens, \\ Greece \\ 3 Department of Biomedical Engineering, University of West Attica, Athens, Greece \\ * Correspondence: Loukas.margaritis@biol.uoa.gr
}

\begin{abstract}
The expanding use of devices emitting Pulsed Telecommunication Signals (PTS) has launched a serious debate over the possible effects of electromagnetic radiation (EMR) on living organisms. Our previous work has indicated that PTS exposure alters Amyloid Precursor Protein (APP) and alpha-synuclein ( $\alpha$-syn) metabolism in human cells of neural origin, providing a possible connection between exposure and neurodegeneration. This investigation aimed to reveal, in vitro in human non-neural cells (HEK293), the aftermath of the same exposure on the processing of APP and $\alpha$-syn. Data presented here, indicate changes in APP metabolism, acquisition of different cellular topologies of the newly generated APP fragments, changes in monomeric $\alpha$-syn accumulation and multimerization, indicating that APP and $\alpha$-syn processing is possibly altered in the periphery by EMR. These effects are accompanied by a substantial increase in the levels of Reactive Oxygen Species (ROS). Further investigation is required in order to provide insights into the interaction of PTS with non-neural cells affecting the peripheral systemic functional stability. This is necessary because nowadays whole body human exposure from various EMR sources is a fact in normal life with the valid estimation that they may be increased in view of the forthcoming $5 \mathrm{G}$ telecommunications network implementation.
\end{abstract}

Keywords: RF/Microwaves; mobile phone; HEK293; APP; $\alpha$-synuclein; oxidative stress; non-ionizing EMR

\section{Introduction}

It has been nearly half a century since the first portable point to point phone communication took place in the streets of New York by Martin Cooper of Motorola. The progress was astonishing thereafter and gradually devices of wireless communications were created, including the cell phones (with the associated base station antennas), the domestic wireless telephones (DECT -Digital Enhanced Cordless Telephone) devices, the Wi-Fi routers, the Tablets, iPads, etc. They all emit "pulsed telecommunication signals" (PTS) and add to the environment a "cloud" of non-ionizing radiation and irradiate human beings in a variety of distances (from skin contact to hundreds of meters), in various field strengths and time duration. The global use of these devices has launched much concern and argument on the possible effects of this kind of daily life radiation on human health and wellbeing through research on biological model systems in vivo, ex vivo or in vitro, as summarized recently by Lloyd Morgan, Lennart Hardell and associates [1]. In vitro studies in general have shown by meta-analysis in 300 peer-reviewed scientific publications (1990-2015) describing 1127 experimental observations in cell-based in vitro models that cellular response varies 
with signal properties [2]. Recent articles elaborate on the parameters of real world PTS exposure [3-5] but generally, it has been demonstrated that PTS from various domestic sources affects normal functions [6].

With the development and widely used wireless technology, more and more studies are focusing on the relationship between PTS and Alzheimer's disease (AD) in which the Amyloid Precursor Protein (APP) displays the structural characteristics of type I transmembrane glycoproteins [7]. The cleavage of APP through a complex pathway generates the Amyloid beta (Aß) peptide, whereas the detection of $A B$ in neuritic plaques in the brain is the main hallmark of Alzheimer's disease. In that context it was found that electromagnetic pulse exposure induces overexpression of beta amyloid protein in rats [8].

In general the issue of whether the cognitive performance is affected by cell phone exposure has attracted the interest of many scientists from the beginning using in vivo model systems leading to contradictory conclusions [9]; on the one side investigators found that EMR exposure caused clear cognitive and memory impairments compared to the sham exposed group $(p<0.05)$ [10-12] and [13] (and references therein). In addition immunohistochemical (IHC) staining showed increased beta amyloid protein $(\mathrm{A} \beta)$ in EMR exposed groups compared to the sham exposed group, whereas western blot experiments revealed increased expressions of $A \beta$ oligomer and beta amyloid protein precursor (APP) in EMP exposure groups. On the other side a number of reports have shown no effects [14]. Interestingly a few publications support the notion that EMFs ameliorate memory performance $[15,16]$ and that electromagnetic fields disaggregate toxic amyloid beta protein oligomers in brain tissue as part of enhanced mitochondrial function induced by EMFs. [17].

Previous work on PTS irradiated $(1950 \mathrm{MHz})$ neuroblastoma cells has suggested that RF-EMF exposure may not have a significant physiological effect on $\mathrm{A} \beta$ processing of neural cells in the short term [18], whereas our own work using also SY5Y cell line revealed that EMF exposure produces alterations on APP processing and cellular topology [19]. Interestingly, in a recent report [20] it has been shown that specific ranges of electromagnetic field parameters produce peptide conformations unfavourable for amyloid fibrils formation, a phenomenon that can be exploited in treatment and prevention of amyloid diseases

Concerning Parkinson's disease (PD) it is considered the second major, progressive, neurodegenerative disorder that affects $1 \%$ of the over 60 population in industrialized countries [21]. PD neuropathology involves the death of dopaminergic neurons in the substantia nigra, in which intracellular inclusion, termed Lewy Bodies (LB), can be observed [22]. LB's are mainly formed by the aberrant accumulation of $\alpha$-synuclein [23]. It has been shown that neurodegeneration occurs also in nerve cells of the peripheral autonomic ganglia [24]. Indeed, LBs and Lewy neurites are not restricted to the CNS, but can also be observed in the periphery, while monomers of $\alpha$-syn can be detected in body fluids [25]. A-syn is known to exist in tissues outside the CNS including the CSF [26], platelets [27, 28] and plasma [29] but as shown is secreted by externalized vesicles in a calcium-dependent manner [30]

Our recent work investigated the possible effects of PTS exposure emitted by GSM mobile phone in talking mode, on APP and $\alpha$-synuclein in human neuroblastoma cells. Data obtained indicated alterations on APP processing and cellular topology, following EMF exposure. Furthermore, changes in monomeric $\alpha$-synuclein accumulation and multimerization were documented as well as an impressive induction of oxidative stress and cell death, linking for the first time the possible involvement of EMF on the molecular pathogenetic mechanisms associated to Alzheimer's and Parkinson's Diseases [19].The several lines of evidence that support the important functions of APP and $\alpha$-syn in fundamental biochemical pathways, such as metabolic homeostasis and immunity motivated us to proceed to the present investigation, aiming towards the study of the biochemical effects of non-ionizing EMF on APP and alpha-synuclein in non-neural cells. For this reason, Human Embryonic Kidney 293 cells (HEK293) were employed. These cells are a widely used model system for biological and pharmacological applications [31], while they have been previously used to study the effects of PTS ionizing EMR.

Thus based on our previous results [19] and the emerging biochemical value of APP and $\alpha$-syn expression and processing in the maintenance of peripheral functionality, as well as the lack of 
information of the systemic effects of non-ionizing EMR, we proceeded to study APP and $\alpha$-syn metabolism in non-neural cells in vitro .

\section{Results}

\subsection{Effect of non-ionizing PTS EMR on APP processing}

Irradiated cells were kept in the cell culture incubator for 24 hours and then used for protein extraction and Western blot analyses. Immunostaining using the anti-Aß specific antibody (Figure 1), revealed the marked increase in the generation ofa $30 \mathrm{kDa}$ amyloidogenic APP fragment in irradiated samples (L2, L3 in Figure 1). This fragment is barely detectable in sham-exposedcells(Liin Figure 1). Interestingly, there is a remarkable increase of full-length APP that was detected via AB staining at $130 \mathrm{kDa}$, in both exposed samples ( $\mathrm{L}_{2}, \mathrm{~L}_{3}$ in Figure 1$)$ underlying the possibility of altered APP expression patterns in the exposed cells. Furthermore, as far as the staining with the C-terminal antibody and protein band of $\sim 48 \mathrm{kDa}$ is concerned, we detected this fragment only in sham-exposed samples ( $\mathrm{L}_{1}$ in Figure 2) while in the exposed ones of $\mathrm{D}$ and $\mathrm{U}$ configuration, this fragment is hardly detected ( $\mathrm{L}_{2}, \mathrm{~L}_{3}$ in Figure 2). In the exposed cells of the $\mathrm{U}$ configuration(samples that were in closer contact with the EMF source) the generation of a novel $35 \mathrm{kDa}$ C-terminal APP fragment was noted. This fragment was not detected in the sham-exposed and D configuration exposed samples. This observation could imply a positive correlation between the intensity of the field and the severity of the effect. The slight increase of the C-terminal $63 \mathrm{kDa}$ fragment in the U configuration, further supports the EMF induced modification on APP processing. These data could indicate that EMF exposure affects both expression and metabolism levels of APP in HEK 293. Interestingly, it has been reported that APP C-terminal fragments could serve as transcription factors [32] affecting gene expression.
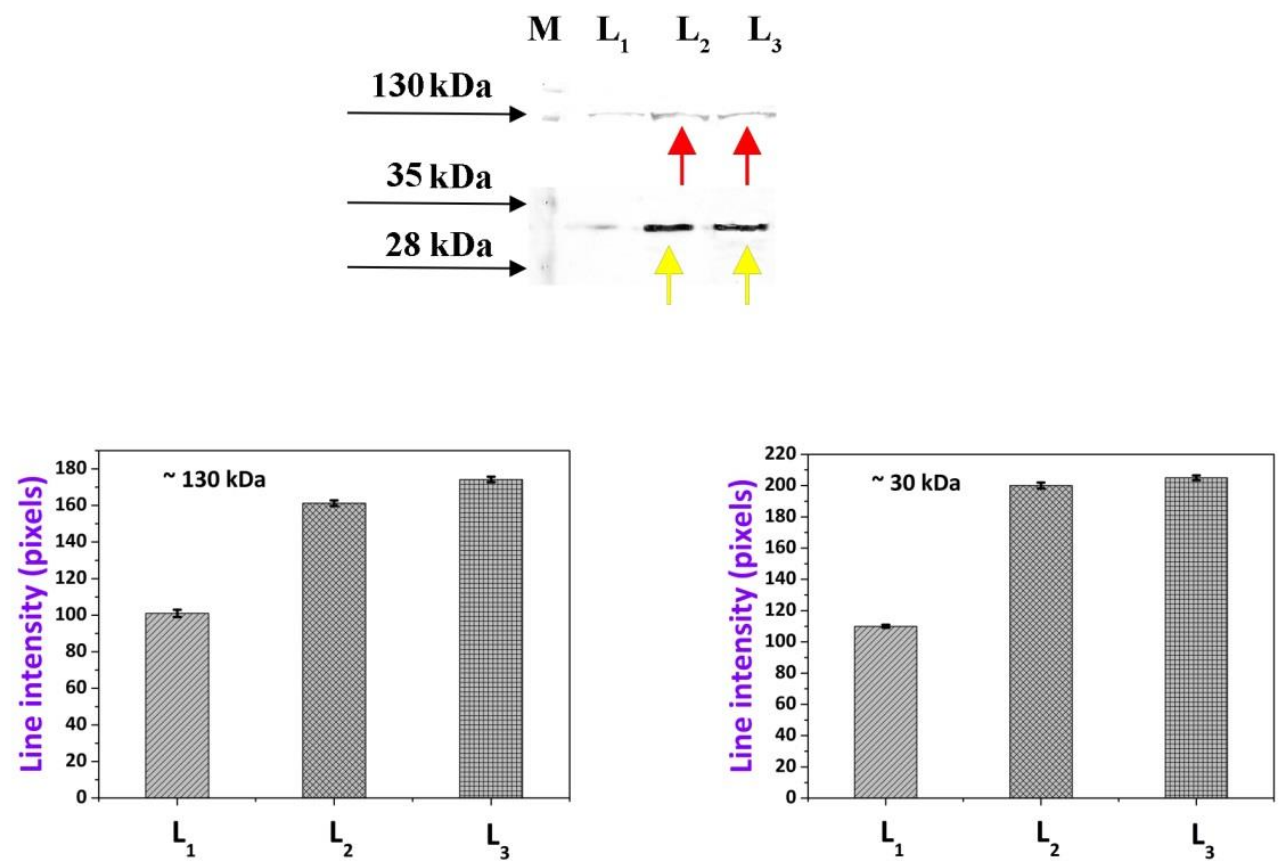

Figure 1. Effect of non-ionizing PTS radiation on APP processing in HEK293 cells. Immunodetection was carried out using the anti-Aß specific antibody.(M: MW marker; L1: sham-exposed cells; L2: exposed cells in down configuration; L3: exposed cells in the up configuration. Quantification of protein bands of 130 and $30 \mathrm{kDa}$ are illustrated in bar graphs; error bars represent the standard error of the mean - SEM. 


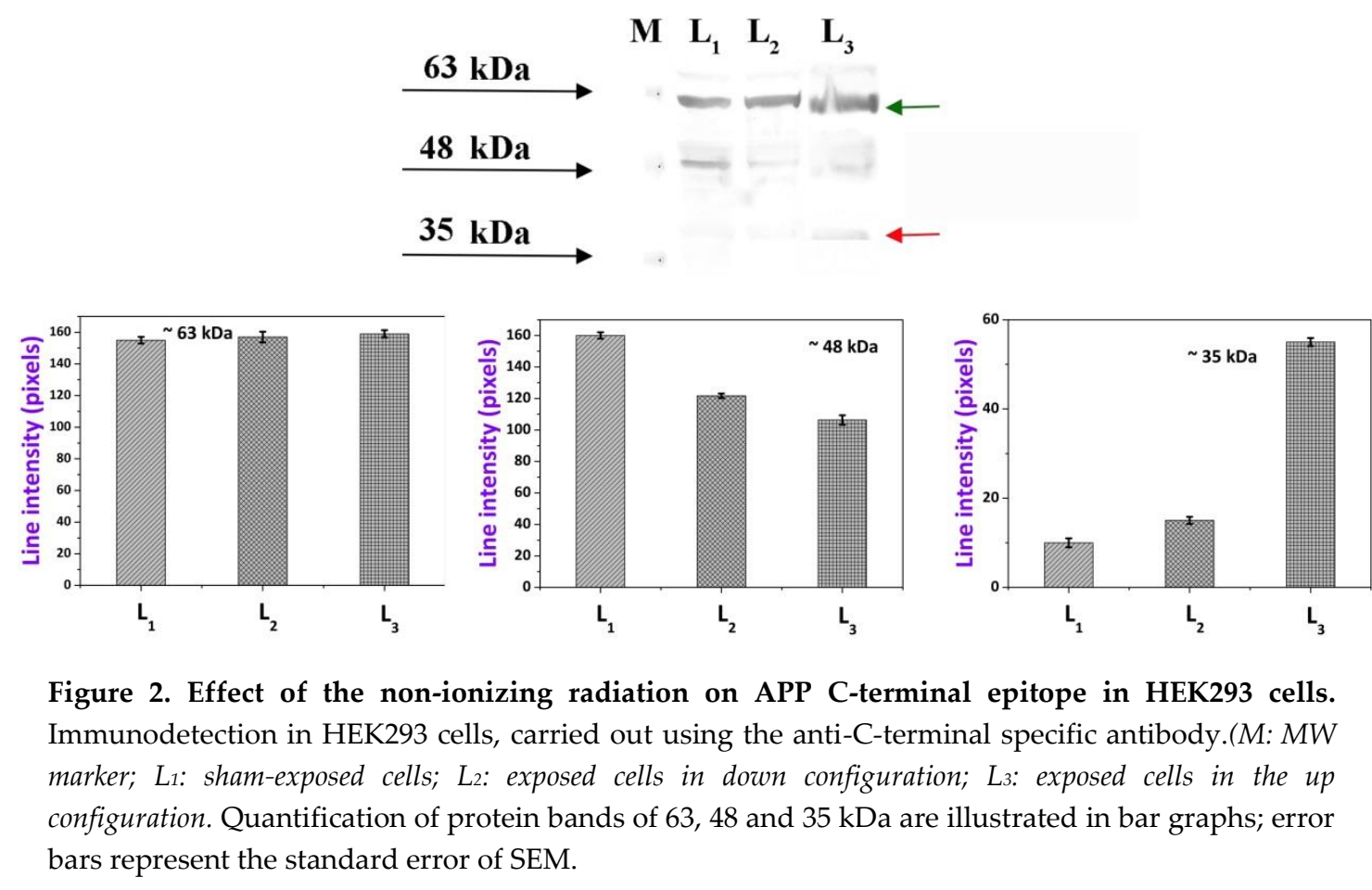

\subsection{Effect of PTS EMR on APP cellular topology}

It is a well-known fact that a protein'scellular topology is crucial for protein-protein interactions and other important cellular functions, including signal transduction. Themodificationof the cellular environment that a protein molecule is located at, affects cellular functions and pathways that the molecule is involved in. Following our observations that APP processing is altered in the exposed samples, we proceeded to investigate if these biochemical alterations included changes in cellular topology. Figure 3, Panel a, depicts immunostaining with the anti-Aß specific antibody in sham-exposed cells, Panel b,in exposed cells in D configuration and Panel c, in exposed cells in U configuration. In these panels, $\mathrm{L}_{1}$ represents the Triton X-114 detergent-depleted (aqueous) phase, $\mathrm{L}_{2}$ the Triton X-114 detergent-enriched phase and $\mathrm{L}_{3}$ the Triton X-114 insoluble -phospholipid enriched-phase. In Figure 3a, the same distribution of amyloidogenic fragments in three phases for sham-exposed samples could be easily noticed. Interestingly, in the exposed samples (D configuration) there is an increase in AB reactive APP fragment which is recovered in all phases mainly though, in the hydrophobic and highly hydrophobic phases (Figure 3b). In contrast to " $\mathrm{D}$ " exposed cells, in exposed cells ofthe U configuration, where the intensity of the EMF was higher, the amyloidogenic fragment recovered in the aqueous phase is hardly detected ( $\mathrm{L}_{1}$ in Figure 3c), whereas there is an equal distribution (as compared to sham-exposed samples) of this $A B$ reactive APP fragment both in hydrophobic and highly hydrophobic phases respectively ( $\mathrm{L}_{2}$, $\mathrm{L}_{3}$ in Figure 3c). As can be seen (Figure 3) there is a shift of these newly generated amyloidogenic fragments from hydrophilic environments to hydrophobic and highly hydrophobic cellular compartments, following irradiation. This observation could be interpreted as a possible change of amyloidogenic fragments and therefore the generation of new interactions with other molecules and ligands. 

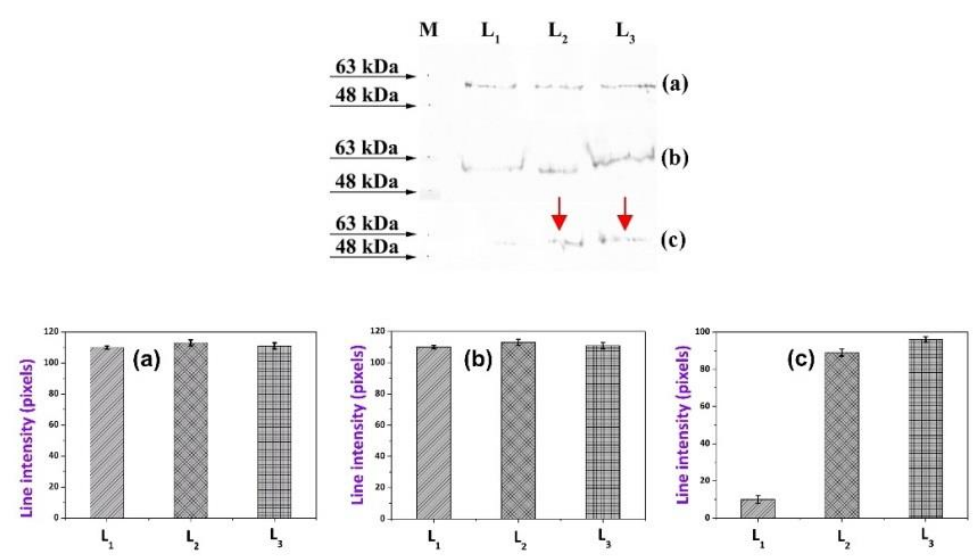

Figure 3. Temperature-induced phase separation of proteins from HEK293 cells in Triton X-114.

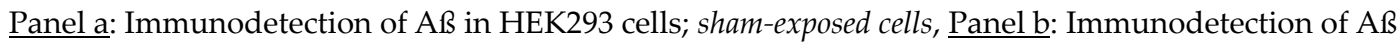
in HEK293 cells; exposed cells in down configuration and Panel c: Immunodetection of Aß in HEK293 cells; exposed cells in up configuration. (M: MW marker; L1: Triton X-114 detergent-depleted (aqueous) phase; L2: Triton X-114 detergent-enriched phase; L3: Triton X-114 insoluble (phospholipid-enriched) phase). Quantification of three panels $(\mathrm{a}, \mathrm{b}, \mathrm{c})$ for all samples is illustrated in bar graphs; error bars represent the standard SEM.

\subsection{Effect of PTS EMR on $\alpha$-syn multimerization in HEK293 cells}

Aggregations of oligomers of $\alpha$-syn in Lewy bodies have been recognized as the hallmarks of PD. As stated above, the biochemical spectrum of $\alpha$-syn functions is increasing and expanding to the immune system, renal function, gene regulation, development, etc. To investigate any possible effect of non-ionizing EMR in the oligomerization procedure of this highly dynamic protein, western blot analyses and immunodetection using the anti- $\alpha$-syn specific antibody was employed (Figure 4 ). Our results demonstrated a remarkable increase in expression levels of the toxic $\alpha$-syn monomers [33] following irradiation. In sham-exposed $\left(\mathrm{L}_{1}\right)$ samples a-syn is detected only in its multimeric form while no $\alpha$-syn monomers are detected. To our surprise, in exposed HEK293, a remarkable expression of the monomers of $\alpha$-syn ( 16 kDa-yellow arrows in Figure 4), both in D and U samples, was detected. Furthermore, in exposed samples, we detected a remarkable increase in $\alpha$-syn multimers in the form of $\alpha$-syn dimers ( $35 \mathrm{kDa}$-green arrows in Figure 4$)$, trimers (purple arrows) and tetramers of $\alpha$-syn ( $\sim 64 \mathrm{kDa}$-red arrows) according to Sharon [34]. This remarkable increase of $\alpha$-syn monomers and multimers is highly detected in our results in the $\mathrm{U}$ configuration samples and this increase is related to the intensity of EMF. Our data could indicate that EMF emerges as a new contributor to altered $\alpha$-syn metabolism in non-neural cells and raises the possibility that EMF contributes to pathogenetic mechanisms in cells other than the CNS. 


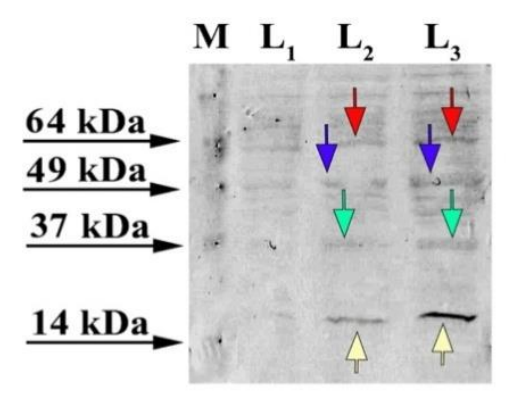

HEK293
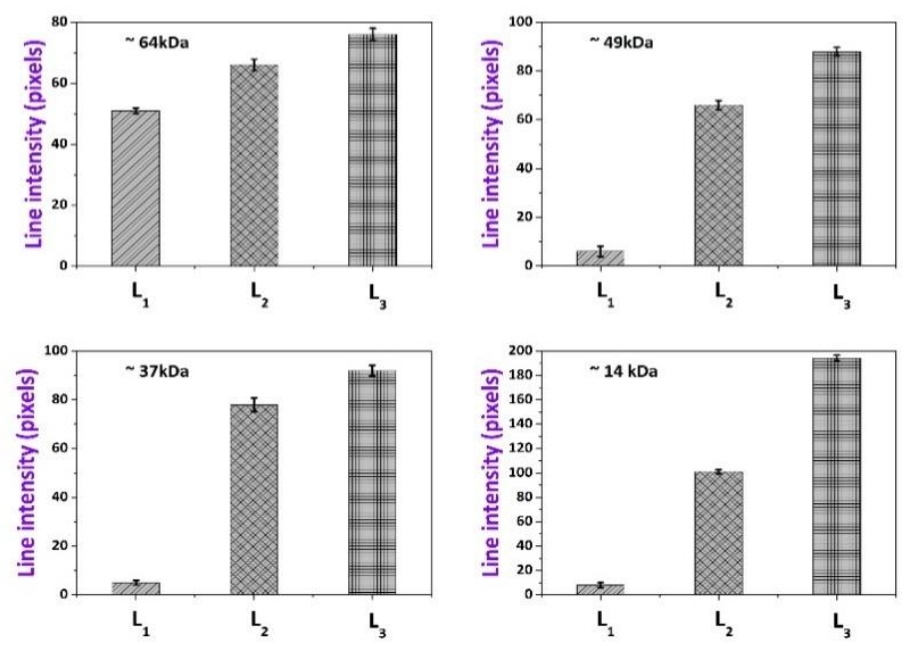

Figure 4. Effect of PTS EMR on $\alpha$-synuclein multimerization. Immunodetection was carried out using the anti- $\alpha$-synuclein specific antibody. (a): Immunodetection in HEK293 cells; (M: MW marker; L1: sham-exposed cells; L2: exposed cells in down configuration; L3: exposed cells in up configuration). Error bars represent the standard error of SEM.

\subsection{Effect of PTS EMR on Programmed Cell Death-Apoptosis}

Furthermore, to investigate the possibility that exposure to EMR involves apoptosis ( Programmed Cell Death)we proceeded to test our samples for the expression of caspase -3 using the anti-caspase-3 antibody. Caspase-3 is an executioner caspase and is activated in the apoptotic cell by extrinsic and intrinsic pathways [35]. In HEK293 exposed samples, the expression of caspase-3 is remarkably increased (L2, L3in Figure 5a), as compared to the sham-exposed ones (L2, L3in Figure 5a). This remarkable increase in the expression of caspase- 3 implies the possible activation of apoptotic pathways.
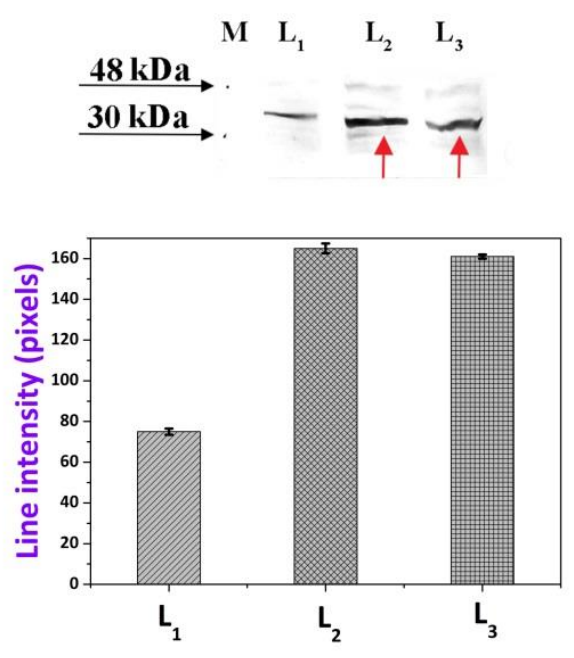
Figure 5. Effect of PTS EMR on Programmed Cell Death. Immunodetection was carried out using the anti-caspase-3 specific antibody. (a): Immunodetection in HEK293 cells; (M: MW marker; L1: sham-exposed cells; L2: exposed cells in down configuration; L3: exposed cells in up configuration). Error bars represent the standard error of the mean - SEM.

A significant increase in cell death was induced by radiation exposure (Figure 6a). as detected after treatment with Trypan blue. These findings strengthen the observation of the aspect that non-ionizing EMR induces cytotoxicity.

\subsection{Effect of PTS EMR on ROS production}

EMR has been "accused" of oxidative stress induction in many species. Thus, ROS measurements were necessary to confirm this event in our experiments. ROS content was increased in all exposed samples. Interestingly, in the exposed cells in U configuration, where the intensity of the EMF is about 3 times higher, the ROS content was found to be higher in all circumstances (Figures 6b).
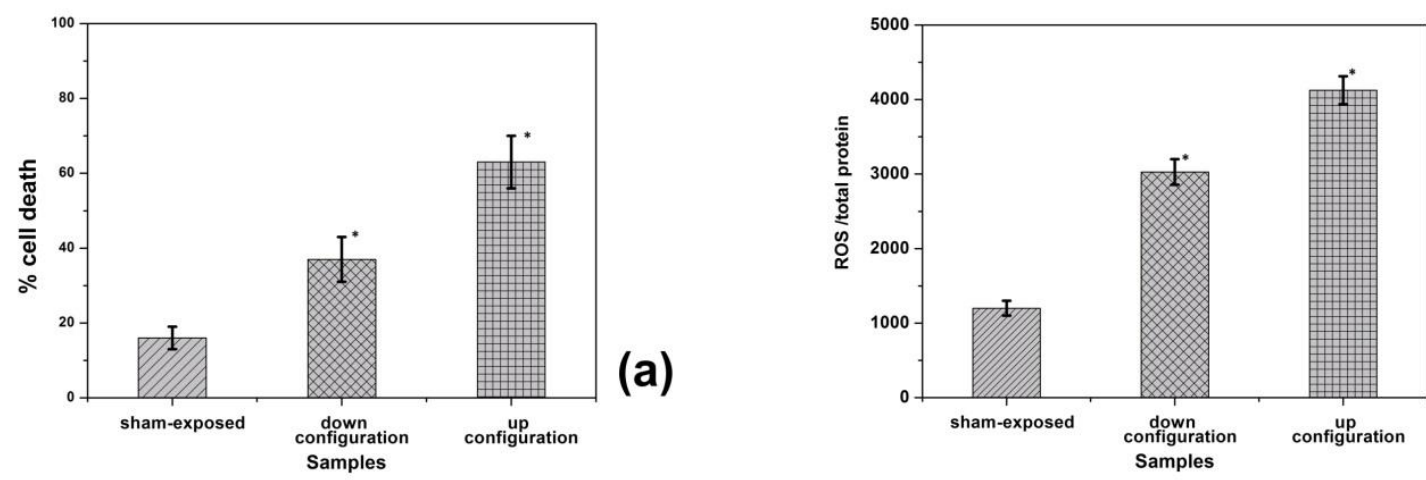

Figure 6. The effect of mobile phone radiation on cellular toxicity and the oxidative stress of HEK293 cell cultures. Bar graph showing the \% cellular toxicity and ROS levels normalized in percentage compared to the sham-exposed values. Results expressed as the mean \pm SD from three independent experiments. Comparisons were made between sham-exposed and irradiated cultures using Student's paired t-test where significance was recorded as $\mathrm{p} \leq 0.05\left(^{*}\right)$.Error bars represent the standard error of the mean (SEM). (a): Cellular toxicity in HEK293 cells; (b): ROS levels in HEK293 cells.

\section{Discussion}

Since 1998, when ICNIRP issued the guidelines and the limits of secure exposure, taking into consideration only the thermal effects of non-ionizing EMR, many researchers were swiveled towards the non-thermal effects of this type of radiation [36,37].Twenty years later, there is an accumulating body of evidence suggesting that non-ionizing EMR induces - in all circumstances - an imbalance between reactive oxygen species in cells and their antioxidant mechanisms, leading to a situation known as oxidative stress both in animal and plant cells [19, 38-40] although ICNIRP's recent overview still suggests the same more or less safety margins [41, 42]. However, as admitted by the authors of the recent ICNIRP paper [42] the guidelines were designed to protect only from short-term heating (or thermal) effects and not from non-thermal effects, especially from long-term exposure to wireless radiation because ICNIRP continues to dismiss the many hundreds of peer-reviewed studies that have found biological and health effects from exposure to low-intensity, radio frequency radiation including many human as well as animal studies. The preponderance of the so far research has found evidence of increased cancer incidence, oxidative stress, DNA damage, and infertility from exposure to wireless PTS since, unlike ICNIRP's belief non thermal effects exist upon exposure to low levels of electromagnetic radiation [38, 43]. It is true however that most EMR experiments are restricted to selected effects according to the model system used that dictates the 
actual information retrieval approaches. In addition no real time conditions exit (as described explicitly in [44] unlike the approach used herein. This may explain in part the contradictory data presented in the literature.

\subsection{APP metabolism and cellular topology}

Exposure of HEK293 in the EMF of a mobile phone modified the APP metabolism. APP is widely expressed not only in the brain but also in the periphery. In non-neural cells, the amyloid pathway of APP is intracellular, while BACE1 is more active there [45]. In the data presented here, exposed HEK293 cells (U configuration, highest intensity) resulted in the generation of a new amyloidogenic fragment $(\sim 30 \mathrm{kDa})$. This observation indicated a modification in C-terminal APP proteolytic processing (Figure 2). Furthermore, our data pointed towards the possibility that the expression of full-length APP is also modified (Figure 2). As mentioned above, C-terminal APP fragments (Figure 2) are related to cell differentiation and transcription regulation [32]. Accordingly, the observed altered APP metabolism pattern, induced by EMF exposure, could contribute either to the misregulation of transcription or dysfunction of cell differentiation. Modification of APP the proteolytic processing has also been shown to be subsequent to exposure to ionizing radiation, particularly UV radiation, where the acceleration of proteolysis of endogenous APP by gamma-secretase has been reported [46]; in the mouse C57BL/6J animal model used in this report, this alteration of APP metabolism, following exposure of corneal neurons to ultraviolet radiation, resulted eventually in axonal transport damage.

Although neuronal cells are considered to be the main "pool" of the amyloid beta peptide, endothelial cells are also able to generate Aß [47]. Interestingly, Aß peptides implement a crucial role in insulin metabolism and diabetes. Downregulation of insulin receptors located on the cell membrane surface results in inefficient insulin binding [48]. Furthermore, some authors [49] support the notion that APP overexpression and dysregulation in adipocytes of obese humans is related to insulin resistance, thus linking the increasing risk for $\mathrm{AD}$ development with obesity, inflammation, and insulin resistance. Epithelial cells in the liver affect $A B$ brain levels via modifications of blood $A B$ concentration. Therefore impaired hepatic $A ß$ degradation has emerged as a new peripheral factor that contributes to the pathogenesis of $\mathrm{AD}[50]$.

Alteration in the cellular topology of amyloidogenic fragments (Figure 3, is a remarkable effect of EMF exposure on human cells of neural origin (SH-SY5Y; [19]. This new amyloidogenic fragment cellular distribution could imply novel interactions that could result in the creation of novel functions of these fragments. It is known that biological function is closely related to the topology of molecules [51].

\subsection{A-syn oligomerization}

HEK293 cells' exposure to EMR, generated by a mobile phone in talking mode, revealed a very impressive result. Namely the multimerization of $\alpha$-syn generating aggregates of different molecular weights (Figure 4). Our data demonstrate a possible equilibrium interruption between the $\alpha$-syn monomers and multimers following irradiation. Furthermore, the dramatic increase of $\alpha$-syn multimers ranging from $37 \mathrm{kDa}$ to $>64 \mathrm{kDa}$ indicated a change in $\alpha$-syn multimerization regulation pathways and/or a dysregulation of the molecular interactions governing the generation of $\alpha$-syn multimeric species. As mentioned above, Lewy bodies' $\alpha$-syn is the hallmark of PD [52]. Although it has been reported that $\alpha$-syn tetramers have a small possibility to contribute to aggregates formation [53].the dramatic increase in toxic monomeric $\alpha$-syn could greatly contribute to the increased levels of multimerization observed in our results following exposure. Although dePomerai [54] did not find any synuclein aggregation following two modes of exposure in the nematode C. elegans, we have to point out that this model system is largely resistant to Radiofrequency exposure as found by our own experimental data [55].

Alpha-synuclein is present not only in the brain but also in a plethora of organs and tissues such as the peripheral nervous system [56], liver, muscle, kidney, lungs, heart, hematopoietic cells of the bone marrow, circulating blood cells and adipose cells [57]. Thus, many biological functions, far 
from the synapse one, have been attributed to $\alpha$-syn, such as regulation of gene expression [58] and apoptosis, modulation of glucose and calmodulin levels [59] are among the most representative. Furthermore, $\alpha$-syn appears to have important roles in the periphery, involving in the prenatal development of peripheral tissues. Interestingly, peripheral expression levels of this pleiotropic molecule start to decline as development proceeds except for the kidneys, the adrenal glands, and the testis. In adults, $\alpha$-syn remains present in the periphery but the levels are considerably lower as compared to the expression levels in the adult brain [60]. In the current research alpha-synuclein dimers $(37 \mathrm{kDa})$ and trimers $(50 \mathrm{kDa})$ are observed to be generated in the exposed cultures of the HEK293 cells. These similar $\alpha$-syn species are involved in the prenatal development of peripheral tissues in both rats and humans. The $\alpha$-syn species are absent from fetal and adult human brains and adult rat brain [60]. Interestingly, these multimers could not be traced in normal human brains but only in brains of individuals affected by neurodegenerative diseases such as PD, PD/AD, and therefore they are considered to be generated during the pathogenesis of these disorders [61]. The multimerization of $\alpha$-syn has a crucial role in the immune system and its homeostasis. These $\alpha$-syn species cause cytokines secretion misregulation without affecting the inflammatory responses, which result in the activated microglia, inflammation and neurodegeneration observed in PD [62].

The migration of $\alpha$-syn monomers and multimers from the enteric nervous system to CNS where they contribute to the substantia nigra destruction via inflammation, underlines the cross-talk between the periphery and the CNS as reported recently [63]. Our data which clearly show a marked increase in the toxic monomeric and multimeric $\alpha$-syn species in the non-neural human cells in vitro system used, could imply that EMF exposure is a possible participant in the pathogenic mechanisms that alpha-synuclein is participating in the periphery and a possible added contributor in neurodegeneration.

\subsection{ROS and cellular toxicity}

Cellular metabolism is based on electron transport redox reactions. If these non-paired electrons are massively produced or/and the antioxidants do not scavenge them, the excess in their energy is transported in other molecules in the "form" of ROS which generates oxidative stress conditions. Some brain areas contain high levels of Fe, which can be used to catalyze the generation of ROS [64]. The brain is also enriched in lipids with unsaturated fatty acids, which are potential targets for lipid peroxidation [65]. Furthermore, the brain does not have substantial antioxidant defense systems, compared to other organs such as the liver and kidneys, containing only moderate levels of superoxide dismutase (SOD), catalase and glutathione peroxidase. In AD, the level of Glutathione (GSH) in peripheral lymphocytes is decreased [66]. Another useful piece of information is that the frequencies used in the current study $(900$ and $1.800 \mathrm{MHz})$ can penetrate the skull of humans - the younger the individual the more the penetration [67] - and therefore it might be possible that the outcome of the in vitro experiments may be similar to an in vivo application.

Our results of real life repetitive exposure of HEK293 to PTS using a mobile phone, resulting in an increase of ROS agree with in vivo studies in kidney cells of Male Wistar Albino rats, exposed to EMF of $900 \mathrm{MHz}\left(1.04 \mathrm{~mW} / \mathrm{cm}^{2}\right)$ resulted in ROS induction [68].The increase in ROS content as a result of the exposure of cells to the EMF of a mobile phone, has also been observed in human umbilical cord blood-derived monocytes (1800 MHz, SAR $=2 \mathrm{~W} / \mathrm{kg}$ for 30 or 45 minutes) [69], in monocytes from peripheral blood (900 MHz, for 2 hours) [70] and in human spermatozoa [71], where the increase in ROS considered to be the main factor affecting sperm malfunction.

Furthermore, the increase in ROS content is related to the intensity of the field (see Figure 6). Carefully designed configuration in this work since an identical PST mode in space and time was given simultaneously to two different culture flasks under different field strength. I.e. in the irradiation protocol we applied two different exposure configurations at the same time (upper flask with the cells in bottom-close to the cell phone front side vs, down flask with cells $2 \mathrm{~cm}$ away from the backside of the phone). Thus positive correlation was identified between the intensity of the applied field and the severity of the induced ROS effect. The results presented in this study, are in agreement with our previously reported data on the neural cell line SH-SY5Y (SAR = 0,23 W/kg) - 
[19] and also with a study on human monocytes exposed to $900 \mathrm{MHz}$ ( $\mathrm{SAR}=0,43 \mathrm{~W} / \mathrm{kg}$ ), where the increase in ROS content was related to the duration of the field [72].

Apoptosis (Programmed Cell Death) is mediated by caspases and is closely related to oxidative stress [73]. Our results revealed the induction of apoptosis in HEK293 cells and agree with other investigators which have shown that exposure of human lymphocytes in EMF (915 MHz) led to the induction of apoptosis [74]. Furthermore, exposure of human fibroblasts [75] and human endothelial cells EA hy926 to EMF generated by mobile phone $(900 \mathrm{MHz})$, caused multiple gene activation, including caspase-3 [76]. Along these lines it is mentioned that hallmarks of apoptosis, such as DNA fragmentation and caspase- 3 activation have been described in the brains of $A D$ patients [77-78]. Our data showed cell death induced by radiation indicating its role in cytotoxicity even under the safety margins suggested by ICNIRP [42].

\subsection{Limitations of the study}

As stated by Kostoff 44] the wealth of data gathered so far on the effects of cell phone - like radiation suffers from variations of the model systems used and the exposure conditions which are largely non-realistic utilizing simulated conditions, ie mostly signal generators and the so called TEM-cells ensuring homogenous electromagnetic field. However this is not the case in real life cell phone exposure conditions. Our experimental setup is in contrary using real communication signals deriving from commercial cell phones in actual calling and talking conditions. Power densities are measured during experiments and used for SAR calculation and is the same throughout different experiments since GSM protocol is designed to regulate exposure power according to the quality of the signal received by the nearest available base station. Under this logic it is hard to replicate experiments in another lab/location/country unless the same cell phone and signal conditions are used which is unlikely. On the other hand the advantages of this exposure setup rely on the real life conditions used.

\section{Materials and Methods}

\subsection{Cell cultures}

HEK293 (Human Embryonic Kidney) cells, obtained from ATCC $®$,and were cultured in Dulbecco's Modified Eagle's Medium (DMEM, PAA Laboratories ${ }^{\mathrm{TM}}$ E15-009). DMEM was supplemented with 10\% heat-inactivated Fetal Bovine Serum (FBS Gibco ${ }^{\mathrm{TM}}, 10500064$ ) while 100 $\mathrm{U} / \mathrm{ml}$ penicillin/streptomycin $\left(\mathrm{Gibco}^{\mathrm{TM}}, 15140122\right)$ were also added.A SANYO ${ }^{\mathrm{TM}}$ CO2incubator(model MCO-15AC-Sanyo Electric Co Ltd) was used for the maintenance of cell cultures in a humidified atmosphere of $5 \% \mathrm{CO}_{2}$ at $37^{\circ} \mathrm{C}$. The medium was replenished three times per week.

\subsection{Exposure Setup - Dosimetry - SAR Estimation}

HEK293 cells were placed into a sterilized laminar flow hood for irradiation using a mobile phone (GSM 1800MHz) in talking mode. Two flasks with cells from the same passage (P8-P15) were placed on the upside and the downside of the mobile phone. Thus, they were designated as irradiated cells in up (U) configuration and irradiated cells in down (D) configuration accordingly. The average intensity of the electric field in the samples exposed in the U configuration was 3 times higher $(10,51 \mathrm{~V} / \mathrm{m})$ as compared to the $\mathrm{D}$ exposed ones $(3,50 \mathrm{~V} / \mathrm{m}$ - figure $1 \mathrm{in} \mathrm{[19].} \mathrm{The} \mathrm{total} \mathrm{exposure}$ duration was $60 \mathrm{~min}$ for two consecutive days (first day: 10 min exposure, rest $20 \mathrm{~min}, 10 \mathrm{~min}$ exposure, rest $20 \mathrm{~min}$ and a last $10 \mathrm{~min}$ exposure after which the flasks were put back in their incubator. The same exposure protocol was applied on the second day, same day time.). After the last exposure, the flasks were put back in their incubator. A sham-exposed set of cultures consisted of 2 flasks that were treated for 10 minutes in the same laminar flow hood under identical conditions, with one main difference; mobile phone was turned off (and the subscriber identifier module-SIM-card was removed). The entire experimental setup, as well as the dosimetry, has been described in detail in [19]. Twenty-four hours following the last irradiation, cells were collected from 
flasks for immediate ROS estimation and cellular toxicity measurements or were stored at $-20^{\circ} \mathrm{C}$ for SDS-PAGE electrophoreses and western blotting analyses.

\subsection{Antibodies}

The Anti-APP specific antibodies were raised in the laboratory of one of the authors (DV) against the $A ß$ peptide and the C-terminal regions of human APP. The antibody against human $\alpha$-syn (MFCD02095740 - S3062) and the secondary antibody (MFCD00162782) were purchased from Sigma-Aldrich ${ }^{\mathrm{TM}}$, (Milan, Italy).All reagents used in the current study were of analytical grade.

\subsection{Protein extraction}

Protein extraction from exposed and sham-exposed samples was performed using RIPA lysis buffer (Thermo Fisher Scientific Inc. - NYSE: TMO, 89900). Samples were centrifuged (12.000 x g, 10 $\min , 4^{\circ} \mathrm{C}$, 3 times) and supernatants were stored at $-20{ }^{\circ} \mathrm{C}$. Bradford's method [79] was used for the determination of total protein, using bovine serum albumin as standard.

\subsection{Temperature-induced phase separation in Triton X-114}

The non-ionic detergent Triton X-114 was used to perform phase partition [80]. Triton X-114 (Sigma-Aldrich $^{\mathrm{TM}}$, Milan, Italy, 9036-19-5) was pre-condensed to remove any hydrophilic contaminants. Proteins were extracted from cell cultures as described above (sham-exposed and exposed samples), and were resuspended in ice-cold TBS (10 mM Tris- $\mathrm{HCl}, 150 \mathrm{mM} \mathrm{NaCl}, \mathrm{pH} 7.2)$. The detergent was added at a $2 \%$ concentration. The mixture was incubated for 15 minutes at room temperature, occasionally mixed in an ice bath. Samples were consequently centrifuged at $13.000 \times \mathrm{g}$ for 10 minutes at $4^{\circ} \mathrm{C}$. After centrifugation, three different phases emerged; a) phospholipid rich phase /Triton X-114 insoluble (pellet), b) the detergent-depleted or the upper phase and c) the detergent-enriched or lower phase. Samples from all three phases were subjected to western blotting analyses.

\subsection{Western Blot Analysis}

SDS-PAGE electrophoresis and subsequent immunoblotting were performed on a "Biorad Mini Protean" electrophoresis apparatus as described by Laemmli [78], using either 10\% or 15\% polyacrylamide slab gel. Electrophoresis was carried out at $90 \mathrm{~V}$ for 3 hours at room temperature. Samples were then transferred onto nitrocellulose [79]. The classic method of Batteiger [80] was used for the immunodetection of the enzymes described above. The Bluestar prestained marker (Nippon Genetics, Tokyo) was used as an indicator of the molecular weight of proteins during protein separation and electrophoresis and immune transfer.

\subsection{Quantification}

To proceed to the quantification of the immunodetection signals the "Image Pro Plus" v.10.0 software was employed.Each band intensity was measured 5 times for statistics (standard error of the mean).Measured data (in pixels) were illustrated in bar graphs, using the software "Origin Lab Pro" v.9.0.

\subsection{Reactive Oxygen Species measurements}

The induction of oxidative stress as a possible effect of non-ionizing EMR was measured using the oxidant sensitive fluorescent acetyl ester CM-H ${ }_{2}$ DCFDA (5 -(and-6)- chloromethyl-2', $7^{\prime}$ -dichlorodihydrofluorescein diacetate) dissolved in DMSO. The whole procedure for the ROS measurements is described in detail in [19]. The results were expressed as the average of three independent experiments and were illustrated in bar graphs, generated in the "OriginLabPro, v.9.0"

\subsection{Cell cytotoxicity}


The Trypan Blue exclusion method was employed to determine anypossible effect of non-ionizing electromagnetic radiation in cell death and the results were expressed as the average of three independent experiments, illustrated in bar graphs, generated using the "OriginLabPro, v.9.0". The percentage of the observed cytotoxicity was calculated according to the following formula [84].

$$
\% \text { Dead }=\frac{\text { Number of colorless cells }}{\text { Total number of cells }} \cdot 100
$$

\subsection{Statistical analysis}

The SPSS v.21.0 software (SPSS Inc., Chicago, IL) was used for the statistical analysis; analysis was performed by employing separate t-tests comparing the sham-exposed group to each one of the exposed groups. Differences in mean scores were analyzed using a one-way analysis of variance (ANOVA). Data were expressed as mean \pm S.D. and evaluated by Student's $t$-test; differences were considered as statistically significant when $\mathrm{p}<0.05$.

\section{Conclusions}

The current investigation links exposure of Pulsed Telecommunication Signals emitted by a mobile phone in call mode, with the altered metabolism of APP and alpha-synuclein in a non-neural cell model HEK293. We have to point out that the pulses refer to the actual DCS protocol information pulses as shown in our previous work [16] and not to the $217 \mathrm{~Hz}$ ELF power saving pulses described in a similar recent study by Zielinski [85]. Our work shows a connection between altered APP and $\alpha$-syn metabolism of non-neural (kidney) human cells exposed to a Pulsed Telecommunication Signal from an ordinary cell-phone during a normal 10min long. The non-ionizing radiation applied on the cultured cells as a result of the specific exposure conditions used was under non-thermal levels within ICNIRP's safety guidelines [42]. The present findings are very importance since as we have demonstrated by electron microscopy, cell-produced alpha-synuclein is secreted via an exosomal, calcium-dependent mechanism suggesting that alpha-synuclein secretion serves to amplify and propagate Parkinson's disease-related pathology [86]. The generation of novel amyloidogenic fragments along with a differential cellular distribution, in addition to the induction of cellular toxicity, apoptotic marker expression and the induction of oxidative stress, triggers a novel alarm concerning the risk from the widely used PTS wireless technology which will be greatly exploding after the implementation of the forthcoming $5 \mathrm{G}$ networks. Our data are in line with the skepticism expressed by a large number of scientists worldwide who characterize the uncontrolled use of electromagnetic radiation by manmade devices as a threat to human health as well as the environment.

Author Contributions:“Conceptualization, LHM. and DV.; methodology, ALS, ASS and LHM.; validation, DV, ALS and LHM.; formal analysis, ALS and ASS.; investigation, DV and LHM; resources, DV and LHM.; data curation, ALL.; writing-original draft preparation, ALS.; writing-review and editing, LHM and DV.; visualization, X.X.; supervision, DV and LHM.; project administration, DV.; funding acquisition, LHM. All authors have read and agreed to the published version of the manuscript.",

Funding. This research has been co-financed by the European Union (European Social Fund-ESF) and Greek National funds through the Operational Program "Education and Life-long Learning" of the National Strategic Reference Framework (NSRF)-Research Funding Program: THALES. Investing in knowledge society through the European Social Fund. UoA-MIS 375784: "Biological effects of nonionizing electromagnetic fields: a multi-disciplinary approach" grant coordinated by Prof. L.H. Margaritis.

Conflicts of Interest: "The authors declare no conflict of interest."

\section{Abbreviations}

AD Alzheimer's Disease

APP Amyloid Precursor Protein

Aß beta amyloid peptide 


$\begin{array}{ll}\text { CNS } & \text { Central Nervous System } \\ \text { DCS } & \text { Digital Cellular telecommunications System } \\ \text { EMF } & \text { ElectroMagnetic Field } \\ \text { EMR } & \text { ElectroMagnetic Radiation } \\ \text { IARC } & \text { International Agency for Research on Cancer } \\ \text { ICNIRP } & \text { International Commission on Non-Ionizing Radiation Protection } \\ \text { LB } & \text { Lewy Bodies } \\ \text { PD } & \text { Parkinson's Disease } \\ \text { PTS } & \text { Pulsed Telecommunication Signal } \\ \text { ROS } & \text { Reactive Oxygen Species } \\ \alpha \text {-syn } & \text { alpha-synuclein } \\ 5 G & 5^{\text {th }} \text { generation telecommunication network }\end{array}$

\section{References}

1. Miller AB, Sears ME, Morgan LL, Davis DL, Hardell L, Oremus M, et al. 2019 Risks to health and wellbeing from radio-frequency radiation emitted by cell phones and other wireless devices. Frontiers in Public Health.:223. DOI:10.3389/fpubh.2019.00223

2. Halgamuge MN, Skafidas E, Davis D (2020) A meta-analysis of in vitro exposures to weak radiofrequency radiation exposure from mobile phones (1990-2015). [temp.] Environ Res 2020; 184: 109227

3. Wall S, Wang ZM, Kendig T, Dobraca D, Lipsett M. 2018.Real-world cell phone radiofrequency electromagnetic field exposures. Environ Res. 2019 Apr;171:581-592. doi: 10.1016/j.envres. 09.015. Epub 2018 Oct 3.PMID: 30448205

4. Chiaramello E, Bonato M, Fiocchi S, Tognola G, Parazzini M, Ravazzani P, Wiart J 2019 Radio Frequency Electromagnetic Fields Exposure Assessment in Indoor Environments: A Review.Int J Environ Res Public Health. Mar 17;16(6):955. doi: 10.3390/ijerph16060955.

5. Ramirez-Vazquez R, Gonzalez-Rubio J, Arribas E, Najera A 2019 Characterisation of personal exposure to environmental radiofrequency electromagnetic fields in Albacete (Spain) and assessment of risk perception..Environ Res.May;172:109-116. doi: 10.1016/j.envres.2019.02.015.

6. Margaritis LH, Manta AK, Kokkaliaris KD, Schiza D, Alimisis K, Barkas G, Georgiou E, Giannakopoulou O, Kollia I, Kontogianni G, Kourouzidou A, Myari A, Roumelioti F, Skouroliakou A, Sykioti V, Varda G, Xenos K, Ziomas K Drosophila oogenesis as a bio-marker responding to EMF sources Electromagn Biol Med 2014; 33 (3): 165-189

7. Robakis, N.K., Ramakrishna, N., Wolfe, G., Wisniewski, H.M., 1987. Molecular cloning and characterization of a cDNA encoding the cerebrovascular and the neuritic plaque amyloid peptides.Proc. Natl. Acad. Sci. U. S. A. $84,4190-4194$

8. Jiang DP, Li J, Zhang J, Xu SL, Kuang F, Lang HY, Wang YF, An GZ, Li JH, Guo GZ (2013) Electromagnetic Pulse Exposure Induces Overexpression of Beta Amyloid Protein in Rats Arch Med Res 2013; 44 (3): 178-184

9. Guxens M, Vermeulen R, van Eijsden M, Beekhuizen J, Vrijkotte TGM, van Strien RT, Kromhout H, Huss A.2016 Outdoor and indoor sources of residential radiofrequency electromagnetic fields, personal cell phone and cordless phone use, and cognitive function in 5-6 years old children.Environ Res. 2016 Oct;150:364-374. doi: 10.1016/j.envres.2016.06.021.

10. Fragopoulou, A. F., Samara, A., Antonelou, M. H., Xanthopoulou, A., Papadopoulou, A., Vougas, K., Koutsogiannopoulou, E., Anastasiadou, E., Stravopodis, D.J., Tsangaris, G.T., Margaritis, L.H., 2012. Brain proteome response following whole body exposure of mice to mobile phone or wireless DECT base radiation.Electromagn Biol Med. 31(4), 250-74.

11.Luria, R., Eliyahu, I., Hareuveny, R., Margaliot, M., Meiran, N., 2009. Cognitive Effects of Radiation Emitted by Cellular Phones: The Influence of Exposure Side and Time. Bioelectromagnetics. 30(3),198-204. 
12. Ntzouni, M.P., Skouroliakou, A., Kostomitsopoulos, N., Margaritis, L.H., 2013. Transient and cumulative memory impairments induced by GSM $1.8 \mathrm{GHz}$ cell phone signal in a mouse model. Electromagn. Biol. Med. 32(1), 95-120

13. Schoeni A, Roser K, Röösli M. 2015 Memory performance, wireless communication and exposure to radiofrequency electromagnetic fields: A prospective cohort study in adolescents Environ Int. Dec;85:343-51. doi: 10.1016/j.envint.2015.09.025. Epub 2015 Oct 30.

14. Son Y, Jeong YJ, Kwon JH, Choi HD, Pack JK, Kim N, Lee YS, Lee HJ.2016. 1950 MHz radiofrequency electromagnetic fields do not aggravate memory deficits in 5xFAD mice.Bioelectromagnetics. 2016 Sep;37(6):391-9. doi: 10.1002/bem.21992. Epub 2016 Jul 19.

15. Arendash GW et al. (2010): Electromagnetic field treatment protects against and reverses cognitive impairment in Alzheimer's disease mice. J. Alzheimers Dis. 19:191-210.

16. Arendash, G.W. (2016) Review of the Evidence That Transcranial Electromagnetic Treatment Will Be a Safe and Effective Therapeutic Against Alzheimer's Disease. J Alzheimers Dis 30;53(3):753-71.

17. Jeong YJ, Kang GY, Kwon JH, Choi HD, Pack JK, Kim N, Lee YS, Lee HJ (2015)1950 MHz Electromagnetic Fields Ameliorate Abeta Pathology in Alzheimer's Disease Mice.Curr Alzheimer Res 2015; 12 (5): 481-492

18. Park J, Kwon JH, Kim N, Song K2018Effects of $1950 \mathrm{MHz}$ radiofrequency electromagnetic fields on A $\beta$ processing in human neuroblastoma and mouse hippocampal neuronal cells. J Radiat Res 59 (1): 18-26

19. Stefi, A.L., Margaritis L.H., Skouroliakou, A., Vassilacopoulou, D., 2019. Mobile phone electromagnetic radiation affects Amyloid Precursor Protein and $\alpha$-synuclein metabolism in SH-SY5Y cells. Pathophysiology. https://doi.org/10.1016/j.pathophys.2019.02.004

20. Todorova N., Bentvelzen A., Yarovsky I. Electromagnetic field modulates aggregation propensity of amyloid peptides. 2020 J. Chem Phys 152(3), 035104

21. de Lau, L., Breteler, M., 2006. Epidemiology of Parkinson's disease.Lancet Neurol. 5(6), 525-535.

22. Wichmann, T., Smith, Y., Vitek, J., 2008. Basal ganglia: anatomy and physiology, in:Factor, S., W. Weiner, W. (Eds.),Parkinson's disease: diagnosis and clinical management (2nd Edition), Demos Medical Publishing, Inc., New York.pp. 246-258

23. Spillantini, M.G., Schmidt, M.L., Lee, V.M., Trojanowski, J.Q., Jakes, R., Goedert, M,.(1997). Alpha-synuclein in Lewy bodies.Nature, 388, 839-40.

24. Wakabayashi, K., Matsumoto, K., Takayama, K., Yoshimoto, M., Takahashi, H., 1997. NACP, a presynaptic protein, immunoreactivity in Lewy bodies in Parkinson's disease. Neurosci Lett. 239(1), 45-48.

25. Malek, N., Swallow, D., Grosset, K.A., Anichtchik, O., Spillantini, M., Grosset, D.G., 2014. Alpha-synuclein in peripheral tissues and body fluids as a biomarker for Parkinson's disease: a systematic review. Acta Neurol Scand. 130(2), 59-72

26. Borghi, R., Marchese,R., Negro, A.,Marinelli, L.,Forloni, G.,Zaccheo,D., Abbruzzese, G.,Tabaton, M., 2000.Full length alpha-synuclein is present in cerebrospinal fluid from Parkinson's disease and normal subjects. Neurosci. Lett. 287, 65-67.

27. Hashimoto, M., M. Yoshimoto, A. Sisk, L.J. Hsu, M. Sundsmo, A. Kittel, T. Saitoh, A. Miller, E. Masliah, (1997) NACP, A synaptic protein involved in Alzheimer's disease, is differentially regulated during megakaryocyte differentiation, Biochem. Biophys. Res. Commun. 237, 611-616

28. Park, S.M.,Jung, H.Y.,Kim, H.O.,Rhim, H.,Paik, S.R.,Chung, K.C.,Park, J.H.,Kim, J. 2002.Evidence that alpha-synuclein functions as a negative regulator of $\mathrm{Ca}(++)$-dependent alpha-granule release from human platelets.Blood 100, 2506-2514.

29. El Agnaf, O.M., Salem, S.A.,Paleologou, K.E.,Cooper,L.J., Fullwood, N.J.,Gibson, M.J.,Curran, JM.D., Court, A.,Mann, D.M.,Ikeda, S.,Cookson, M.R.,Hardy, J.,Allsop, D., 2003.Alpha-synuclein implicated in Parkinson's disease is present in extracellular biological fluids, including human plasma, FASEB J. 17, 1945-1947.

31. Hu, J., Han, J., Li, H., Zhang, X., Liu, L., Chen, F., Zeng, B., 2018. Human Embryonic Kidney 293 Cells: A Vehicle for Biopharmaceutical Manufacturing, Structural Biology, and Electrophysiology. Cells Tissues Organs.205,1-8. doi: 10.1159/000485501

32. Willnow, T., Petersen, C. Nykjaer, A., 2008.VPS10P-domain receptors - regulators of neuronal viability and function. Nat Rev Neurosci 9, 899-909 doi:https://10.1038/nrn2516.

33. Killinger, B.A., Melki, R., Brundin, P.Kordower,J. H.,2019. Endogenous alpha-synuclein monomers, oligomers and resulting pathology: let's talk about the lipids in the room. Parkinsons Dis. 5, 23 doi:10.1038/s41531-019-0095-3 
34. Sharon, R., Bar-Joseph, I., Frosch, M.P., Walsh, D.M., Hamilton, J.A., Selkoe, D.J., 2003. The formation of highly soluble oligomers of $\alpha$-synuclein is regulated by fatty acids and enhanced in Parkinson's disease. Neuron.37 (4), 583-595.

35. Bratton, S. B., Walker, G., Srinivasula, S. M., Sun, X.M., Butterworth, M., Alnemri, E.S., Cohen, G.M., 2001.Recruitment, activation and retention of caspases- 9 and -3 by Apaf- 1 apoptosome and associated XIAP complexes.EMBO J.20(5), 998-1009.

36. Belyaev I, Dean A, Eger H, Hubmann G, Iandrisovits R, Kern M, Kundi M, Moshammer H, Lercher P $\underline{\text { Müller K}}$, Oberfeld G, Ohnsorge P $\underline{\text { Pelzmann P }}$ Scheingraber C, Thill R. 2016 EUROPAEM EMF Guideline 2016 for the prevention, diagnosis and treatment of EMF-related health problems and illnesses. $\underline{\text { Rev }}$ Environ Health. 2016 Sep 1;31(3):363-97. doi: 10.1515/reveh-2016-0011.

37. Belpomme, D., Hardell, L., Belyaev, I., Burgio, E., Carpenter, D.O., 2018. Thermal and non-thermal health effects of low intensity non-ionizing radiation: An international perspective. Environ. Pollut. 242(Pt A), 643-658. doi: https://10.1016/j.envpol.2018.07.019.

38. Pall M.L. Scientific evidence contradicts findings and assumptions of Canadian Safety Panel 6: microwaves act through voltage-gated calcium channel activation to induce biological impacts at non-thermal levels, supporting a paradigm shift for microwave/lower frequency electromagnetic field action. 2015. Environ Health 30(2):99-116

39. Manta, A. K., Stravopodis, D. J., Papassideri, I. S., Margaritis, L.H., 2014. Reactive oxygen species elevation and recovery in Drosophila bodies and ovaries following short-term and long-term exposure to DECT base EMF. Electromagn Biol. Med. 33 (2), 118-31.

40. Stefi, A.L., Vassilacopoulou, D., Margaritis L.H., Christodoulakis, N.S., 2018.Oxidative stress and an animal neurotransmitter synthesizing enzyme in the leaves of wild growing myrtle after exposure to GSM radiation. Flora. 243, 67-76.

41. ICNIRP, 1998.Guidelines for limiting exposure to time-varying electric, magnetic and electromagnetic fields (up to $300 \mathrm{GHz}$ ).Health Phys. 74, 494-522.

42. ICNIRP, 2020 Guidelines for limiting exposure to electromagnetic fields ( $100 \mathrm{kHz}$ to $300 \mathrm{GHz}$ ). Health Phys $118(5), 483-524$

43. Wust P, Kortüm B, Strauss U, Nadobny J, Zschaeck S, Beck M, Stein U, Ghadjar P Non-thermal effects of radiofrequency electromagnetic fields. temp.2020 Sci Rep; 10 (1): 13488

44. Kostoff R.N., Heroux P., Aschner M., Tsatsakis A. 2020 Adverse Health Effects of 5G Mobile Networking Technology Under Real-Life Conditions Toxicol Lett May 1;323:35-40. doi: 10.1016/j.toxlet.2020.01.020. Epub 2020 Jan 25.

45. Koo, E. H, Squazzo, S. L., 1994. Evidence that production and release of amyloid beta-protein involves the endocytic pathway. J. Biol. Chem. 269, 17386-17389.

46. Almenar-Queralt, A., Falzone, T. L., Shen, Z.,Lillo, C., Killian, R.L,, Arreola, A.S., Niederst, E.D., Ng, K.S., Kim, S.N., Briggs, S.P., Williams, D.S., Goldstein, L.S.,2014. UV irradiation accelerates amyloid precursor protein (APP) processing and disrupts APP axonal transport. J. Neurosci. 34, 3320-3339.

47. d'Uscio,L.V., He, T., Santhanam,A.V., Katusic,Z.S., 2018. Endothelium-specific amyloid precursor protein deficiency causes endothelial dysfunction in cerebral arteries. J Cereb.Blood Flow Metab. 38(10), 1715-1726. doi:https://10.1177/0271678X17735418.

48. Shieh, J.C., Huang, P., Lin, Y., 2020.Alzheimer's Disease and Diabetes: Insulin Signaling as the Bridge Linking Two Pathologies. Mol.Neurobiol. 2020. doi:https://10.1007/s12035-019-01858-5.

49. Lee, Y.H., Tharp, W.G., Maple, R.L., Nair, S., Permana, P.A, Pratley, R.E., 2008. Amyloid precursor protein expression is upregulated in adipocytes in obesity. Obesity (Silver Spring). 16(7), 1493-500.

50. Maarouf,C.L., Walker,J.E., Sue,L.I., Dugger,B.N., Beach,T.G., Serrano,G.E., 2018.Impaired hepatic amyloid-beta degradation in Alzheimer's disease.PLoS One. 2018;13(9):e0203659. doi:10.1371/journal.pone.0203659.

51. Barabási, A. L., Oltvai, Z. N., 2004. Network biology: Understanding the cell's functional organization. Nat Rev Genet. 5(2),101-113.

52. Yasuda, T., Nakata, Y., Mochizuki, H., 2013. $\alpha$-Synuclein and Neuronal Cell Death. Mol.Neurobiol. 47(2), 466-483. https:// 10.1007/s12035-012-8327-0.

53. Bartels, T., Choi, J. G., Selkoe, D. J.,2011. Alpha-synuclein occurs physiologically as a helically folded tetramer that resists aggregation. Nature. 477, 107-110.

54. dePomerai, D. I., Iqbal, N., Lafayette, I., Nagarajan, A., Kaviani Moghadam, M., Fineberg, A., Reader, T., Greedy, S., Smartt, C., Thomas, D.W., 2016. Microwave fields have little effect on $\alpha$-synuclein aggregation 
in a Caenorhabditis elegans model of Parkinson's disease. Bioelectromagnetics. 37, 116-129. doi:https://10.1002/bem.21959

55. Fasseas MK, Fragopoulou AF, Manta AK, Skouroliakou A, Vekrellis K, Margaritis LH, Syntichaki P . Response of Caenorhabditis elegans to wireless devices radiation exposure. 2015 Int J Radiat Biol:91(3) 286-293

56. Alza, N. P., Iglesias González, P. A., Conde, M. A., Uranga, R. M., Salvador, G. A., 2019. Lipids at the Crossroad of $\alpha$-Synuclein Function and Dysfunction: Biological and Pathological Implications. Front Cell Neurosci.13, 175.https://doi:10.3389/fncel.2019.00175.

57. Mohamed Badawy, S. M., Okada, T., Kajimoto, T., Hirase, M., Matovelo, S. A., Nakamura, S., Yoshida, D., Ijuin, T., Nakamura,S.I., 2018. Extracellular a-synuclein drives sphingosine 1- phosphate receptor subtype 1 out of lipid rafts, leading to impaired inhibitory G-protein signaling. J. Biol. Chem. 293, 8208-8216.doi: 10.1074/jbc.RA118. 001986

58. Surguchev, A. A., Surguchov, A., 2017. Synucleins and gene expression:ramblers in a crowd or cops regulating traffic? Front. Mol. Neurosci. 10, 224.doi: 10.3389/fnmol.2017.00224

59. Emamzadeh, F. N., 2016. Alpha-synuclein structure, functions, and interactions.J.Res. Med. Sci. 21, 29.doi: https://10.4103/1735-1995.18198.

60. Baltic, S., Perovic, M., Mladenovic A., RaicevicN., RuzdijicS., RakicL., Kanazir, S.,2004. $\alpha$-Synuclein is expressed in different tissues during human fetal development. J Mol.Neurosci.22, 199.https://doi.org/10.1385/IMN:22:3:199

61. Campbell, B. C., McLean, C. A., Culvenor, J. G., Gai, W. P., Blumbergs, P. C., Jakala, P., Beyreuther, K., Masters,C.L., Li,Q.X.,2001. The solubility of alpha-synuclein in multiple system atrophy differs from that of dementia with Lewy bodies and Parkinson's disease. J. Neurochem. 76, 87-96.

62. Gardai,S.J., Mao, W., Schüle, B., Babcock, M., Schoebel, S., Lorenzana, C., Alexander, J., Kim, S., Glick, H., Hilton, K., Fitzgerald,J.K., Buttini, M., Chiou, S.S., McConlogue, L., Anderson, J.P., Schenk,D.B., Bard, F., Langston,J.W., Yednock, T., Johnston, J.A., 2013. Elevated Alpha-Synuclein Impairs Innate Immune Cell Function and Provides a Potential Peripheral Biomarker for Parkinson's Disease. PLoS ONE 8(8): e71634. https://doi.org/10.1371/journal.pone.0071634

63. Barbut, D., Stolzenberg, E., Zasloff, M., 2019.Gastrointestinal Immunity and Alpha-Synuclein.J Parkinsons Dis. 9(s2), S313-S322.https://doi:10.3233/JPD-191702.

64. Dixon, S. J., Stockwell, B. R., 2014. The role of iron and reactive oxygen species in cell death.Nat. Chem. Biol. 10(1), 9-17.

65. Bourre, J. M., 2010. Diet, Brain Lipids, and Brain Functions: Polyunsaturated Fatty Acids, Mainly Omega-3 Fatty Acids, in: Lajtha, A., Tettamanti, G., Goracci, G. (Eds.), Handbook of Neurochemistry and Molecular Neurobiology.Springer ,US, pp. 409-441.

66. Calabrese, V., Sultana, R., Scapagnini, G., Guagliano, E., Sapienza, M., Bella, R., Kanski, J., Pennisi, G., Mancuso, C., Stella, A.M., Butterfield, D.A., 2006.Nitrosative stress, cellular stress response, and thiol homeostasis in patients with Alzheimer's disease.Antioxid. Redox Signal. 8(11-12), 1975-86.

67. Gandhi, Om. P; Lloyd Morgan, L;Alvaro Augusto de Salles, Yueh-Ying Han, Ronald B Herberman, Devra Lee Davis Exposure limits: the underestimation of absorbed cell phone radiation, especially in children Electromagn Biol Med. 2012 Mar;31(1):34-51.

68. Oktem, F., Ozguner, F., Mollaoglu, H., Koyu, A., Uz, E., 2005. Oxidative damage in the kidney induced by 900-MHz-emitted mobile phone: protection by melatonin. Arc .Med. Res. 36,350-355

69. Lantow, M., Lupke, M., Frahm, J., Mattsson, M.O.,Kuster, N.,Simko, M., 2006. ROS release and Hsp70 expression after exposure to 1,800 $\mathrm{MHz}$ radiofrequency electromagnetic fields in primary human monocytes and lymphocytes. Radiat. Environ. Biophys. 45, 55-62.

70. Kazemi, E., Mortazavi, S. M. J., Ali-Ghanbari, A., Sharifzadeh, S., Ranjbaran, R., Mostafavi-pour, Z., Zal., F., Haghani, M., 2015. Effect of $900 \mathrm{MHz}$ Electromagnetic Radiation on the Induction of ROS in Human Peripheral Blood Mononuclear Cells. J. Biomed. Phys. Eng. 5(3),105-114. 
71. Agarwal, A., Desai, N. R., Makker, K., Varghese, A., Mouradi, R., Sabanegh, E., Sharma, R., 2009. Effects of radiofrequency electromagnetic waves (RF-EMW) from cellular phones on human ejaculated semen: an in vitro pilot study. Fertil.Steril. 92(4), 1318-1325.

72. Lu YS, Huang BT, Huang YX Reactive Oxygen Species Formation and Apoptosis in Human Peripheral Blood Mononuclear Cell Induced by 900 MHz Mobile Phone Radiation. 2012 Oxid Med Cell Longev 740280

73. Oral, B., Guney, M., Ozguner, F., Karahan, N.,Mungan, T., Comlekci, S., Cesur, G,. 2006. Endometrial Apoptosis Induced by a 900-MHz Mobile Phone: Preventive Effects of Vitamins E and C. Adv. Therapy.23, 957

74. Belyaev, I.-Y., Hillert, L., Protopopova, M., Tamm, C., Malmgren, L.O., Persson, B.R., Selivanova, G., Harms-Ringdahl, M., 2005.915 MHz microwaves and $50 \mathrm{~Hz}$ magnetic field affect chromatin conformation and 53BP1 foci in human lymphocytes from hypersensitive and healthy persons. Bioelectromagnetics.26(3), 173-184.

75. Pacini, S., Ruggiero, M., Sardi, I., Aterini, S., Gulisano, F., Gulisano, M., 2002. Exposure to global system for mobile communication (GSM) cellular phone radiofrequency alters gene expression, proliferation, and morphology of human skin fibroblasts. Oncol. Res. 13,19-24.

76. Nylund, R., Leszczynski, D., 2004. Proteomics analysis of human endothelial cell line EA.hy926 after exposure to GSM 900 radiation.Proteomics. 4, 1359-1365.

77. Stadelmann, C., Deckwerth, T. L., Srinivasan, A., et al. (1999). Activation of caspase-3 in single neurons and autophagic granules of granulovacuolar degeneration in Alzheimer's disease.Evidence for apoptotic cell death. Am. J.Pathol. 155(5), 1459-66.

78. Kadowaki, H., Nishitoh, H., Urano, F., Sadamitsu, C., Matsuzawa, A., Takeda, K., Masutani, H., Yodoi, J., Urano, Y., Nagano, T., Ichijo, H., 2005. Amyloid [beta] induces neuronal cell death through ROS-mediated ASK1 activation', Cell Death Differ. 12(1), 19-24.

79. Bradford, M. M., 1976.A rapid and sensitive method for the quantitation of microgram quantities of protein utilizing the principle of protein-dye binding.Anal Biochem.72, 248-254.

80. Bordier, C., 1981. Phase separation of integral membrane proteins in Triton X-114 solution. J. Biol. Chem. 256, 1604-1607.

81. Laemmli, U. K., 1970. Cleavage of structural proteins during the assembly of the head of bacteriophage T4.Nature 227, 680-685.

82. Towbin, H., Staehelin, T., Gordon, J., 1979. Electrophoretic transfer of proteins from polyacrylamide gels to nitrocellulose sheets: procedure and some applications. Proc Natl Acad Sci U S A. 76, 4350-4354

83. Batteiger, B., Newhall, W. Jt., Jones, R. B., 1982 The use of Tween 20 as a blocking agent in the immunological detection of proteins transferred to nitrocellulose membranes. J.Immunol.Methods.55, 297-307.

84. Crowley, L.C., Marfell, B.J., Christensen, M.E., Waterhouse, N.J., 2016.Measuring Cell Death by Trypan Blue Uptake and Light Microscopy.Cold Spring HarbProtoc.doi:https://10.1101/pdb.prot087155

85. Zielinski J, Ducray AD, Moeller AM, Murbach M, Kuster N, Mevissen M 2020 Effects of pulse-modulated radiofrequency magnetic field (RF-EMF) exposure on apoptosis, autophagy, oxidative stress and electron chain transport function in human neuroblastoma and murine microglial cells..Toxicol In Vitro. 2020 Aug 7:104963. doi: 10.1016/j.tiv.2020.104963

86. Emmanouilidou Ev;Melachroinou K; Roumeliotis Th; Garbis S.D.; Ntzouni M.; Margaritis L.H.; Stefanis L.; Vekrellis K. Cell-produced alpha-synuclein is secreted in a calcium-dependent manner by exosomes and impacts neuronal survival. J. Neurosci. 2010 May 19;30 (20):6838-51. doi: 10.1523/JNEUROSCI.5699-09.2010 . 